\title{
Zinc-Catalyzed $\beta$-Allylation of Cyclopropanols via Enolized Homoenolate
}

\author{
Yoshiya Sekiguchi† and Naohiko Yoshikai ${ }^{\dagger+, *}$ \\ 'Division of Chemistry and Biological Chemistry, School of Physical and Mathematical Sciences, Nanyang Technological \\ University, Singapore 637371, Singapore \\ ${ }^{\ddagger}$ Graduate School of Pharmaceutical Sciences, Tohoku University, 6-3 Aoba, Aramaki, Aoba-ku, Sendai 980-8578, Japan
}

\section{Supporting Information Placeholder}

\begin{abstract}
We report herein a zinc-catalyzed $\beta$-allylation of cyclopropanols with Morita-Baylis-Hillman (MBH) carbonates with retention of the cyclopropane ring. The reaction is promoted by a zinc aminoalkoxide catalyst generated from $\mathrm{Et}_{2} \mathrm{Zn}$ and a $\beta$-aminoalcohol, affording cyclopropyl-fused $\quad \alpha$-alkylidene- $\delta$-valerolactone derivatives in moderate to good yields. A bicyclic 1,2disubstituted cyclopropanols undergoes allylation at the sterically more hindered $\beta$-position. This observation, together with other mechanistic experiments, suggest that the present reaction does not proceed via direct $\beta-\mathrm{C}-\mathrm{H}$ cleavage of the cyclopropanol, but rather involves zinc homoenolate and its enolization to generate a key bisnucleophilic species. $\alpha$-Allylation of this "enolized homoenolate" with MBH carbonate would be followed by regeneration of the cyclopropane ring and irreversible lactonization. A sequence of the present reaction and known cyclopropanol transformation provides an opportunity to transform a simple cyclopropanol into $\alpha, \beta$ or $\beta, \beta$-difunctionalized ketones.
\end{abstract}

The cyclopropane ring has attracted the attention of synthetic chemists over decades for its high strain-driven reactivity as well as for its presence in many biologically active substances. ${ }^{1}$ Among all cyclopropanes, cyclopropanols represent unique three-carbon synthons in synthetic methodology development and total synthesis. ${ }^{2}$ They have been extensively explored as precursors to homoenolates and $\beta$-keto radicals, which serve as intermediates of orthogonal reactivity for the synthesis of $\beta$-functionalized ketones (Scheme 1a). The former species are typically generated via ring-opening tautomerization of metal cyclopropoxide, while formation of the latter involves one-electron oxidation to cyclopropoxy radical or its equivalent followed by facile ring opening. Because of the high propensity of cyclopropanols toward these and other ring opening modes, it is difficult to install a new functional group into existing cyclopropanols without rapture of the threemembered ring. This marks a sharp contrast with the extensive development of $\mathrm{C}-\mathrm{H}$ activation of other types of cyclopropanes containing directing groups. ${ }^{3}$

While metal homoenolate has been predominantly used as precursor to $\beta$-functionalized ketones, it is intrinsically amphoteric species that has nucleophilic $\beta$-carbon and electrophilic carbonyl group (Scheme 1a). This amphoteric nature has recently been exploited on several occasions. ${ }^{4}$ A particularly notable example in this context is the zinc-mediated conversion of cyclopropanol to cyclopropylamine by Rousseaux, which elegantly utilized the electrophilicity of the aldehyde allowing the condensation with secondary amine and the nucleophilicity of the carbon-zinc bond allowing the ring closure (Scheme 1b). ${ }^{5}$ Inspired by this and other precedents on zinc homoenolate ${ }^{6}$ and prompted by our own work on catalytic generation of zinc homoenolate, ${ }^{7}$ we wondered if it would be possible to enolize the zinc homoenolate, thus rendering the $\alpha$-carbon nucleophilic (see Scheme 1a). Electrophilic trapping of the resulting bis-nucleophilic, enolized homoenolate at the $\alpha$-position, followed by ring closure of the homoenolate, would furnish a $\beta$-functionalized cyclopropanol. Along with this hypothesis, we have discovered a zinc-catalyzed $\beta$ allylation of a cyclopropanol with a Morita-BaylisHillman carbonate with retention of the cyclopropyl ring, which is reported herein (Scheme 1c). A catalyst generated from $\mathrm{Et}_{2} \mathrm{Zn}$ and a $\beta$-amino alcohol promotes allylation of the $\beta$-position and subsequent lactonization to afford cyclopropyl-fused $\alpha$-alkylidene- $\delta$ valerolactones in moderate to good yields, which overall represents the first example of direct $\mathrm{C}-\mathrm{H}$ functionalization of a cyclopropanol. Mechanistic experiments have proved consistent with the proposed reaction pathway involving $\alpha$-functionalization of the enolized homoenolate.

Scheme 1. Cyclopropanols as Three-Carbon Synthons 
(a) Cyclopropanol as precursor to homoenolate and $\beta$-keto radical

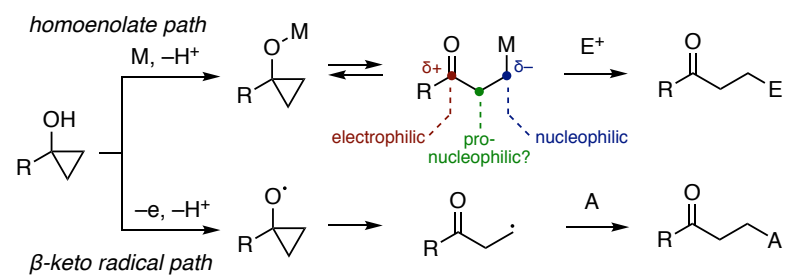

(b) Homoenolate as amphoteric species (Rousseaux)

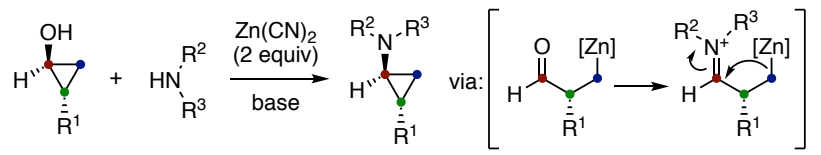

(c) This work: Homoenolate as latent $\alpha, \beta$-bisnucleophile
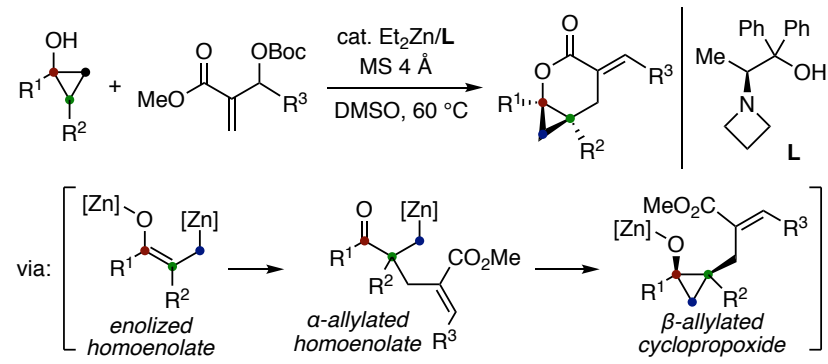

To realize our hypothetical ring-opening $/ \alpha$ functionalization/ring-closure functionalization of cyclopropanol in a catalytic manner, two major requirements, among others, should be satisfied. First, the electrophile should not be directly intercepted by the initially generated zinc homoenolate, but has to wait it to enolize for the desired $\alpha$-functionalization. Second, even if the $\alpha$-functionalization and subsequent ring closure were feasible, the thus-formed cyclopropanol product should not take part in the homoenolate chemistry again, which might lead to multiple substitution or ring-opening decomposition. Retrospectively, MBH carbonate appears to meet these requirements because it lacks reactivity toward organozinc reagents and because its ester moiety allows lactonization with the cyclopropanol, thus irreversibly affording the unreactive product.

Table 1 shows a part of the optimization of the reaction between 1-phenylcyclopropanol (1a) and MBH carbonate (2a) derived from methyl acrylate and benzaldehyde. A catalytic system comprised of $\mathrm{Et}_{2} \mathrm{Zn}(20 \mathrm{~mol} \%)$, alaninederived amino alcohol L1 (20 mol \%), and molecular sieves (MS) $4 \AA$ promoted the reaction in DMSO at $60{ }^{\circ} \mathrm{C}$ to afford [4.1.0]-bicyclic lactone 3aa in $49 \%$ yield (entry 1). The reaction became sluggish in less polar and less coordinating solvents such as THF and toluene (entries 2 and 3). Omission of either MS $4 \AA$ or L1 led to a diminished yield of 3aa (entries 4 and 5). Amino alcohols other than $\mathbf{L 1}$ were as ineffective as the ligand-free system, except that the structurally similar $\mathbf{L 3}$ displayed a comparable performance (entries 6-8). Note that these and other chiral amino alcohols tested induced only modest enantioselectivity (up to $18 \%$ ee; see Table S1). Finally, the yield of 3aa could be improved to $74 \%$ with excess 1a (1.5 equiv), reduced catalyst loadings (10 $\mathrm{mol} \% \mathrm{Et}_{2} \mathrm{Zn}$ and $15 \mathrm{~mol} \% \mathbf{L 1}$ ), and prolonged reaction time (24 h; entries 9 and 10$)$.

Table 1. Zinc-Catalyzed Addition of 1-Phenylcyclopropanol (1a) to Chalcone (2a) ${ }^{a}$

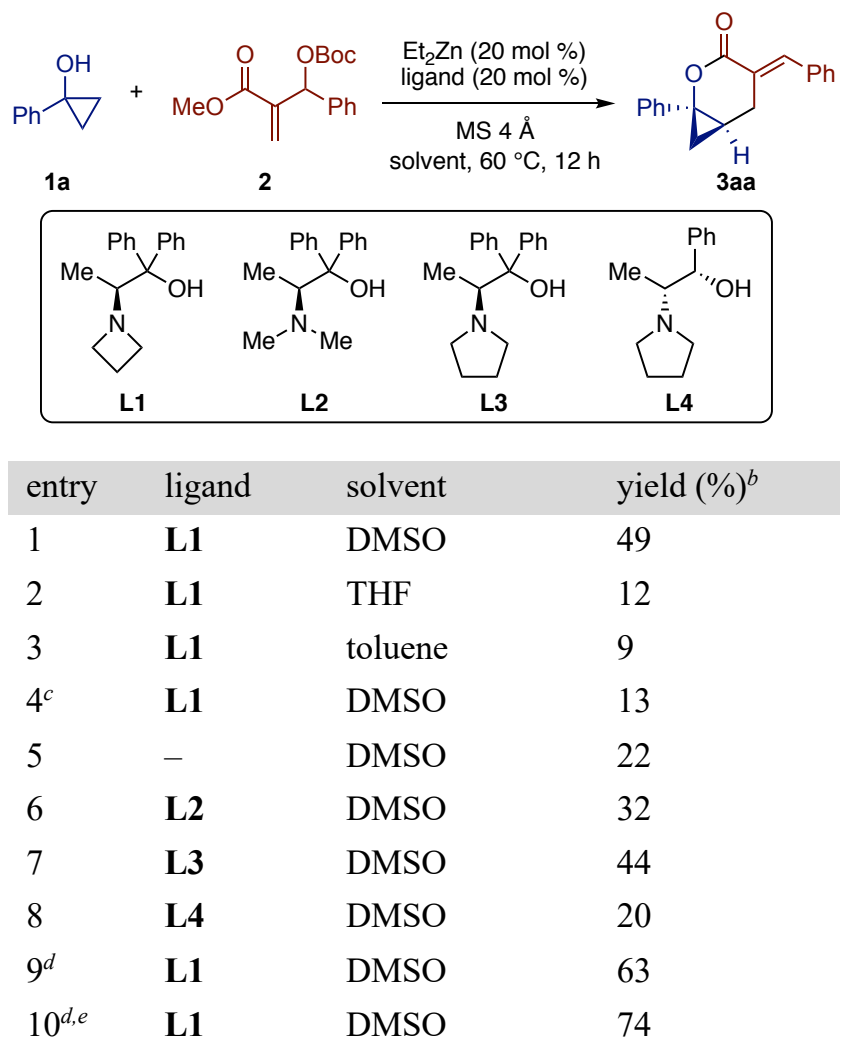

${ }^{a}$ The reaction was performed using $0.10 \mathrm{mmol}$ each of $\mathbf{1 a}$ and $2 \mathbf{a}$ in $0.9 \mathrm{~mL}$ solvent $(0.11 \mathrm{M}) .{ }^{b}$ Determined by GC using mesitylene as an internal standard. ${ }^{c} 4$ A MS was omitted. ${ }^{d} 0.15 \mathrm{mmol}$ of $1 \mathrm{a}$ and $0.10 \mathrm{mmol}$ of $2 \mathrm{a}$ were used. ${ }^{e} 10 \mathrm{~mol} \%$ of $\mathrm{Et}_{2} \mathrm{Zn}$ and $15 \mathrm{~mol} \%$ of $\mathbf{L} \mathbf{1}$ were used. The reaction was performed for $24 \mathrm{~h}$.

With the optimized catalytic system (Table 1, entry 10) in hand, we explored the scope of the present allylation. First, a variety of cyclopropanols were subjected to the reaction with 2a (Scheme 2). A series of 1arylcyclopropanols participated in the allylation to afford the corresponding lactones $\mathbf{3} \mathbf{a} \mathbf{a}-\mathbf{3} \mathbf{j a}$ in moderate to good yields, with tolerance to methyl, iodo, bromo, chloro, and trifluoromethyl groups. Methoxy groups on the meta (3ga) and the ortho (3ha) positions were also tolerated. The reaction of 1 a could be performed on a $5 \mathrm{mmol}$ scale, albeit in a moderate yield (45\%). 1-(2-Naphthyl)- and 1(2-thienyl)cyclopropanols also afforded the desired products 3ia and 3ja, respectively. The molecular structure of the former was unambiguously confirmed by $\mathrm{X}$-ray crystallographic analysis. The latter was difficult to purify by flash chromatography and thus was obtained by recrystallization in modest yield (32\%). 1Alkylcyclopropanols bearing secondary alkyl groups also reacted with $\mathbf{2 a}$ to afford the corresponding products $3 \mathbf{k a}$ and 3la in moderate yields, while the reaction of 1- 
pentylcyclopropanol was complex and failed to give the desired product. Interestingly, bicyclic cyclopropanols $\mathbf{1 m}$ and $\mathbf{1 n}$ underwent allylation with $\mathrm{MBH}$ carbonate $\mathbf{2 m}$ at the more hindered $\beta$-position to afford methanobridged polycyclic lactones $\mathbf{3} \mathbf{m m}$ and $\mathbf{3 n m}$, respectively, in moderate yields. The structure of the latter was confirmed by X-ray crystallographic analysis. Given these results, it appeared less likely that the present reaction proceeded through direct cleavage of the $\beta-\mathrm{C}-\mathrm{H}$ bond (vide infra).

\section{Scheme 2. B-Allylation of Various Cyclopropanols} with MBH Carbonate $2 \mathrm{a}^{a}$

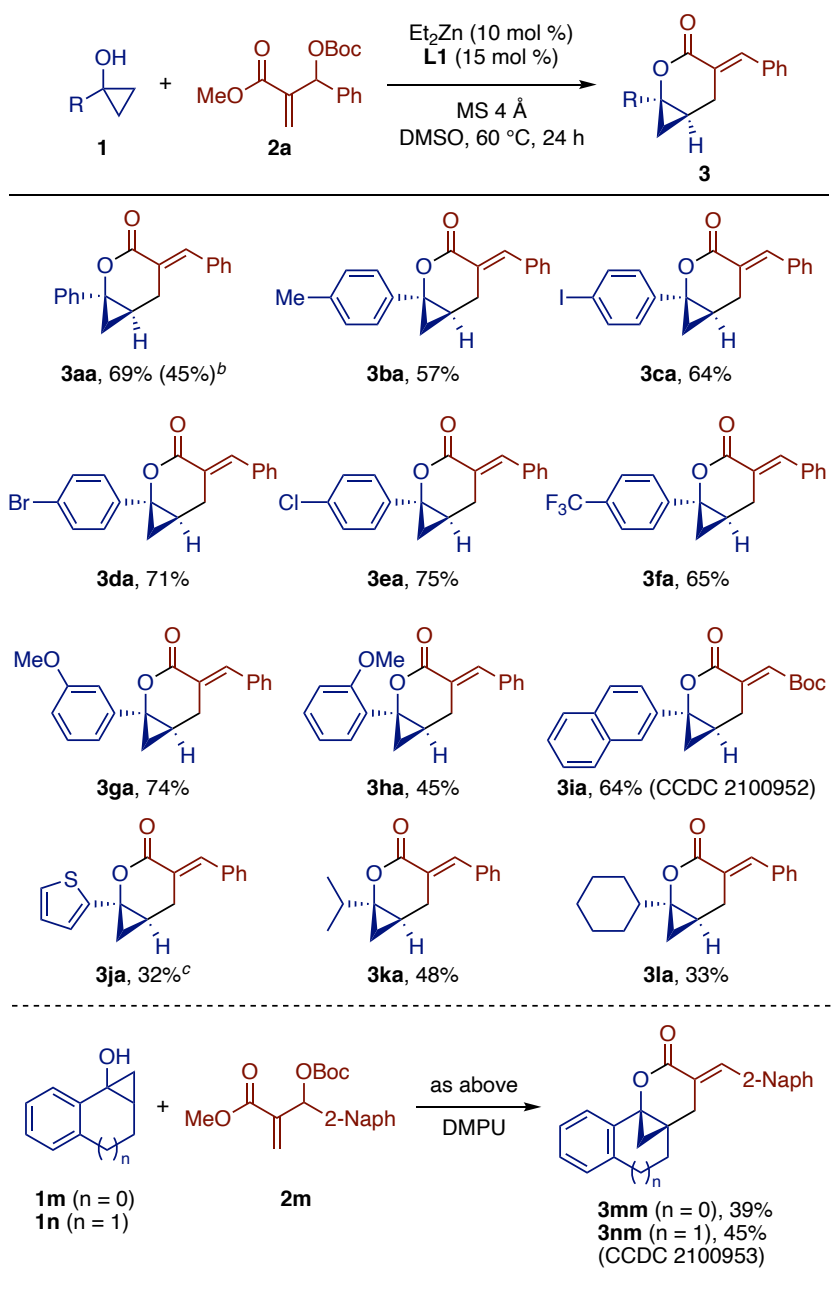

${ }^{a}$ The reaction was performed on a $0.3 \mathrm{mmol}$ scale under the conditions in Table 1, entry $10 .{ }^{b}$ The yield of a $5 \mathrm{mmol}$ scale reaction is shown in the parentheses. ${ }^{c}$ The product was isolated by recrystallization. The yield was based on the obtained crystals.

We next explored the addition of $\mathbf{1 a}$ to various $\mathrm{MBH}$ carbonates (Scheme 3). A series of $\mathrm{MBH}$ carbonates derived from (hetero)aryl aldehydes proved to be good substrates, affording the corresponding bicyclic lactones 3ab-3ag in moderate to good yields. Those derived from aliphatic aldehydes were also tolerated to furnish the products 3ah-3ak, albeit in somewhat lower yields. The formaldehyde-derived $\mathrm{MBH}$ carbonate $\mathbf{2 l}$ also took part in the reaction to give the desired product 3al. It should be mentioned that change of the methyl ester moiety of the MBH carbonate to cyclohexyl or tert-butyl ester led to diminished yields (see Table S1).

Scheme 3. Allylation of Cyclopropanol 1a with Various MBH Carbonates ${ }^{a}$

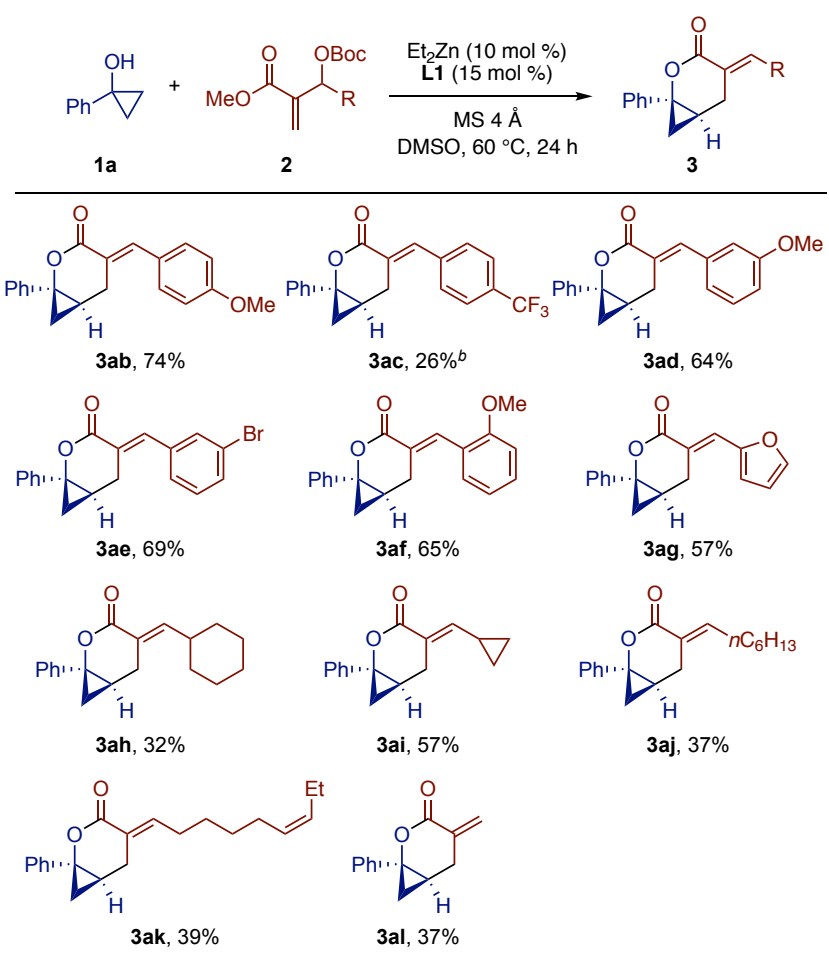

${ }^{a}$ The reaction was performed on a $0.3 \mathrm{mmol}$ scale under the conditions in Table 1, entry $10 .{ }^{b}$ The product was isolated by recrystallization. The yield was based on the obtained crystals.

To gain insight into the mechanism, we performed a series of control experiments. Firstly, we synthesized compounds 4, 5, and 6 to probe the possibility of mechanisms involving either of them as the intermediate (Scheme 4a). The compound $\mathbf{4}$ corresponds to the product of $\alpha$-allylation of propiophenone with the $\mathrm{MBH}$ carbonate 2a, which is a byproduct (12\%) actually obtained in the reaction between 1a and 2a. Another isomer $\mathbf{5}$ is the product of the ring-opening allylation of $\mathbf{1 a}$ with $\mathbf{2 a}$ via homoenolate, which was prepared by our recently developed nickel-catalyzed reaction. ${ }^{8}$ Cyclopropyl ester $\mathbf{6}$ was also synthesized to examine the possibility of an ester exchange between 1a and 2a prior to allylation. In fact, none of 4-6 gave rise to even a trace amount of the lactone 3aa. The failure of $\mathbf{4}$ and $\mathbf{5}$ excludes the possibility of $\beta$-deprotonation and cyclization of the resulting homoenolate to cyclopropoxide, which was unsurprising in light of the low acidity of the $\beta$-position. Meanwhile, the lack of reactivity of $\mathbf{6}$ ruled out a pathway involving ester-directed $\beta$-deprotonation of the cyclopropane ring.

Next, we used an enantioenriched sample (92:8 er) of the cyclopropanol 1n, which was prepared by kinetic 
resolution using $\mathrm{Et}_{2} \mathrm{Zn} / \mathbf{L} \mathbf{4}$ catalyst (see the SI for detail) to probe the stereochemical integrity during the reaction. The reaction of enantioenriched $\mathbf{1 n}$ with $\mathbf{2 m}$ using racemic $\mathbf{L} 1$ afforded a racemic mixture of the product 3nm in 34\% yield (Scheme 4b). This excludes the possibility of direct $\beta$-allylation of $\mathbf{1 n}$ and indicates that the stereochemical information of $\mathbf{1 n}$ is lost through ringopening formation of zinc homoenolate and its enolization (vide infra). Exposure of $\mathbf{1 n}$ to the reaction conditions in the absence of MBH carbonate resulted in conversion ( $52 \%$ in $0.5 \mathrm{~h})$ into its ketone isomer $1 \mathbf{n}$ ' as a near racemic mixture (55:45 er) as well as recovery of $\mathbf{1 n}$ with a partially decreased enantiomeric ratio $(84: 16 \mathrm{er}$; Scheme 4c). While the former observation may be attributable not only to the enolization of homoenolate but also to that of the ketone 1n' itself, the latter appears to reflect the reversibility of the ring-opening and the homoenolate enolization.

\section{Scheme 4. Control Experiments}

(a)

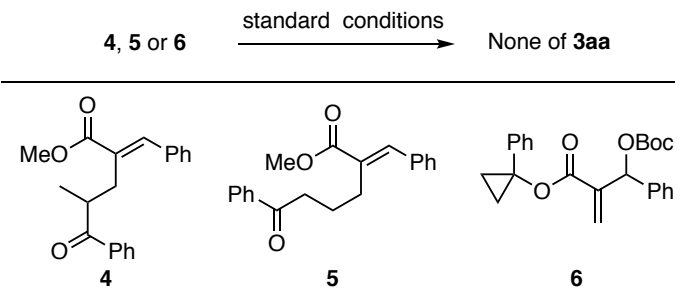

(b)

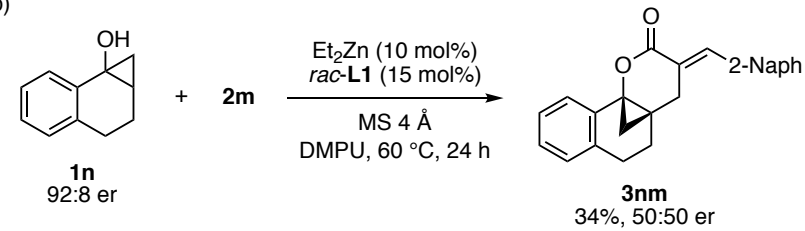

(c)

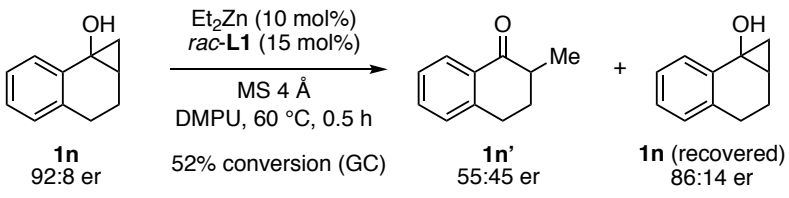

On the basis of the above experiments and previous studies on organozinc/ $\beta$-amino alcohol systems including ours, ${ }^{7,9}$ we propose a catalytic cycle in Scheme $5 . \mathrm{Et}_{2} \mathrm{Zn}$ and $\mathbf{L 1}$ would afford ethylzinc aminoalkoxide $\mathbf{A}$, which would exist in equilibrium with alkoxide-bridged dimer (not shown). Coordination of cyclopropanol $\mathbf{1}$ to $\mathbf{A}$ would give the intermediate $\mathbf{B}$, followed by deprotonation of the cyclopropyl $\mathrm{OH}$ with the internal aminoalkoxide base to generate the cyclopropoxide species C. Homoenolate D, formed by ring-opening of $\mathbf{C}$, would be deprotonated by another molecule of $\mathbf{A}$ to generate the "enolized homoenolate" $\mathbf{E} .{ }^{10}$ Interception of $\mathbf{E}$ with $\mathrm{MBH}$ carbonate 2 would afford $\alpha$-allylated homoenolate $\mathbf{F}$ along with ethylzinc tert-butoxide $\mathbf{J}$, which would regenerate $\mathbf{A}$ by releasing $t \mathrm{BuOH}$. Reconstruction of the cyclopropane ring from $\mathbf{F}$ would be followed by intramolecular transesterification of the cyclopropoxide $\mathbf{G}$ to afford $\mathbf{3}$ and ethylzinc methoxide $\mathbf{H}$, which would release $\mathrm{MeOH}$ and regenerate $\mathbf{A}$. The cyclopropane reconstruction might also take place to generate the trans isomer of $\mathbf{G}$ in a reversible manner, but the overall reaction would be driven by the transesterification of $\mathbf{G}$.

Scheme 5. Possible Catalytic Cycle

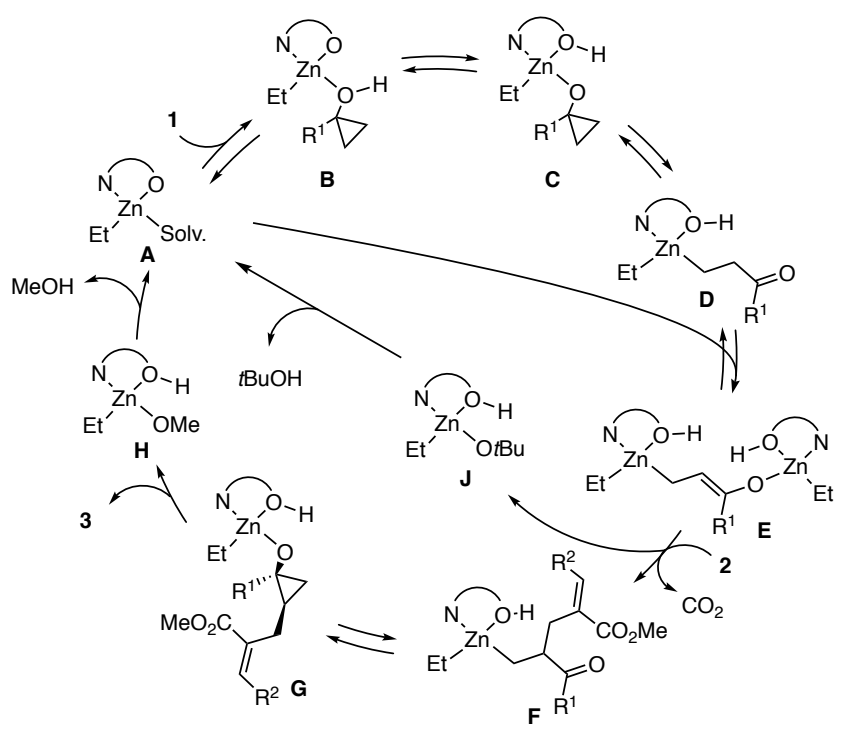

Selected transformations of the product 3aa are shown in Scheme 6a. Reduction of the lactone moiety by DIBAL provided the diol 7 . Treatment with piperidine afforded the cyclopropanol 8 bearing amide moiety in an excellent yield. Basic hydrolysis and subsequent treatment with trimethylsilyldiazomethane furnished the methyl ester $\mathbf{9}$. Note that the compound 9 was not observed in the $\beta$ allylation, pointing to facile transesterification under the reaction conditions. The 1,4-reduction was achieved by DIBAL in the presence of a stoichiometric amount of $\mathrm{Co}(\mathrm{acac})_{2}$ to afford the lactone $\mathbf{1 0}$ as a mixture of separable diastereomers. Furthermore, the $\beta$ functionalized cyclopropanols obtained above could be further exploited as precursors to homoenolate or $\beta$-keto radical. Thus, the nickel-catalyzed reaction of 9 with cinnamyl carbonate ${ }^{8}$ afforded the $\alpha, \beta$-difunctionalized ketone $\mathbf{1 1}$ in good yield (Scheme 6b). Meanwhile, treatment of $\mathbf{8}$ with catalytic $\mathrm{AgNO}_{3}$ and ammonium persulfate ${ }^{11}$ resulted in $\beta$-scission of the more substituted $\mathrm{C}-\mathrm{C}$ bond and oxidative radical cyclization onto the nearby benzene ring to give the $\beta, \beta$-difunctionalized ketone, that is, dihydronaphthalene derivative $\mathbf{1 2}$ (Scheme 6c).

\section{Scheme 6. Product Transformations}


(a)

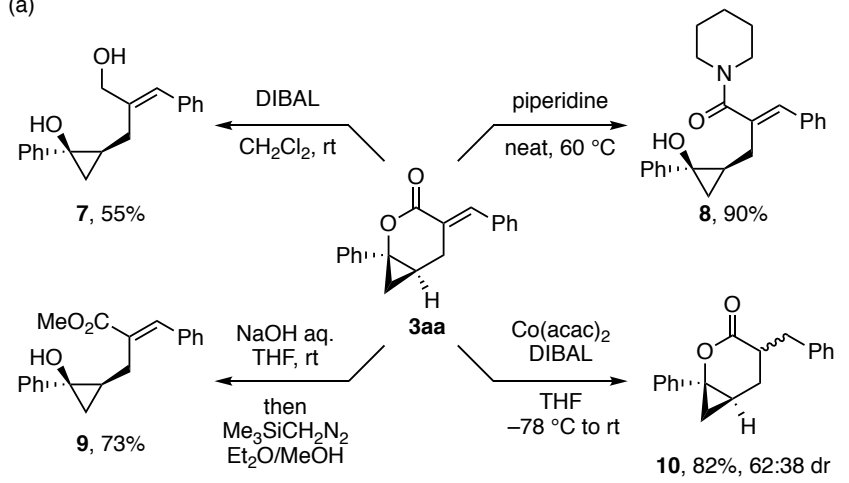

(b)

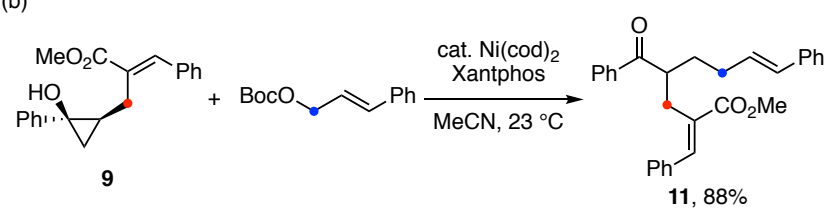

(c)

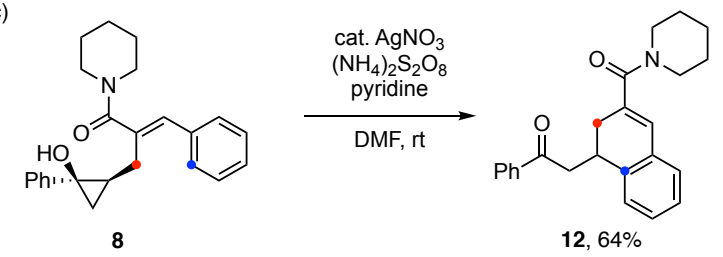

In summary, we have developed a zinc-catalyzed $\beta$ allylation of cyclopropanols with $\mathrm{MBH}$ carbonate without rapture of the cyclopropane ring. The reaction features a ring-opening/ $\alpha$-allylation/ring-closure mechanism involving enolized homoenolate as the key intermediate. The modest electrophilicity of $\mathrm{MBH}$ carbonate as well as its ester functionality has allowed this novel reactivity pattern feasible under catalytic conditions, affording cyclopropane-fused $\alpha$-alkylidene- $\delta$ valerolactone derivatives in moderate to good yields. The mechanistic experiments are consistent with the indirect, roundabout mechanism for the ring functionalization. The small but finite asymmetric induction observed holds promise for the development of an enantioselective variant. While interconversion between homoenolate and enolate represents a common and important process in $\mathrm{N}$ heterocyclic carbene catalysis, ${ }^{12}$ the present reaction represents a rare example of related process in the chemistry of metal homoenolates. Further exploration of metal homoenolate as a latent $\alpha, \beta$-bisnucleophilic species is ongoing in our laboratory.

\section{ASSOCIATED CONTENT}

\section{Supporting Information}

Experimental procedures and characterization data for all the new products (PDF).

\section{Accession Codes}

CCDC 2100952-2100953 contain the supplementary crystallographic data for this paper. These data can be obtained free of charge via www.ccdc.cam.ac.uk/data request/cif, or by emailing data request@.ccdc.cam.ac.uk, or by contacting The
Cambridge Crystallographic Data Centre, 12 Union Road, Cambridge CB1, 1EZ, UK; fax: +44 1223336033.

\section{AUTHOR INFORMATION}

\section{Corresponding Author}

*naohiko.yoshikai.c5@tohoku.ac.jp

\section{Notes}

The authors declare no competing financial interests.

\section{ACKNOWLEDGMENT}

This work was supported by the Ministry of Education (Singapore) and Nanyang Technological University (MOE2016-T2-2-043 and RG101/19). We thank Dr. Yongxin Li (Nanyang Technological University) for his assistance with the X-ray crystallographic analysis.

\section{REFERENCES}

(1) (a) Dian, L.; Marek, I. Asymmetric Preparation of Polysubstituted Cyclopropanes Based on Direct Functionalization of Achiral Three-Membered Carbocycles. Chem. Rev. 2018, 118, 84158434. (b) Fumagalli, G.; Stanton, S.; Bower, J. F. Recent Methodologies That Exploit C-C Single-Bond Cleavage of Strained Ring Systems by Transition Metal Complexes. Chem. Rev. 2017, 117, 9404-9432. (c) Schneider, T. F.; Kaschel, J.; Werz, D. B. A New Golden Age for Donor-Acceptor Cyclopropanes. Angew. Chem. Int. Ed. 2014, 53, 5504-5523. (d) Rubin, M.; Rubina, M.; Gevorgyan, V. Transition Metal Chemistry of Cyclopropenes and Cyclopropanes. Chem. Rev. 2007, 107, 3117-3179.

(2) (a) McDonald, T. R.; Mills, L. R.; West, M. S.; Rousseaux, S. A. L. Selective Carbon-Carbon Bond Cleavage of Cyclopropanols. Chem. Rev. 2021, 121, 3-79. (b) Cai, X.; Liang, W.; Dai, M. Total Syntheses via Cyclopropanols. Tetrahedron 2019, 75, 193-208. (c) Nikolaev, A.; Orellana, A. Transition-Metal-Catalyzed $\mathrm{C}-\mathrm{C}$ and $\mathrm{C}-\mathrm{X}$ Bond-Forming Reactions Using Cyclopropanols. Synthesis 2016, 48, 1741-1768. (d) Sekiguchi, Y.; Yoshikai, N. Metal-Catalyzed Transformations of Cyclopropanols via Homoenolates. Bull. Chem. Soc. Jpn. 2021, 94, 265-280.

(3) Sustac Roman, D.; Charette, A. B. In C-H Bond Activation and Catalytic Functionalization II; Dixneuf, P. H., Doucet, H., Eds.; Springer: 2016, p 91-113.

(4) (a) Yang, J.; Shen, Y.; Lim, Y. J.; Yoshikai, N. Divergent RingOpening Coupling between Cyclopropanols and Alkynes under Cobalt Catalysis. Chem. Sci. 2018, 9, 6928-6934. (b) Yang, J.; Sun, Q.; Yoshikai, N. Cobalt-Catalyzed Regio-and Diastereoselective Formal [3+2] Cycloaddition between Cyclopropanols and Allenes. ACS Catal. 2019, 9, 1973-1978. (c) Davis, D. C.; Walker, K. L.; Hu, C.; Zare, R. N.; Waymouth, R. M.; Dai, M. Catalytic Carbonylative Spirolactonization of Hydroxycyclopropanol. J. Am. Chem. Soc. 2016, 138, 10693-10699. (d) Cai, X.; Liang, W.; Liu, M.; Li, X.; Dai, M. Catalytic Hydroxycyclopropanol Ring-Opening Carbonylative Lactonization to Fused Bicyclic Lactones. J. Am. Chem. Soc. 2020, 142, 13677-13682.

(5) (a) Mills, L. R.; Barrera Arbelaez, L. M.; Rousseaux, S. A. L. Electrophilic Zinc Homoenolates: Synthesis of Cyclopropylamines from Cyclopropanols and Amines. J. Am. Chem. Soc. 2017, 139, 11357-11360. (b) West, M. S.; Lills, L. R.; McDonald, T. R.; Lee, J. B.; Ensan, D.; Rousseaux, S. A. L. Synthesis of trans-2-Substituted Cyclopropylamines from $\alpha$-Chloroaldehydes. Org. Lett. 2019, 21, 8409-8413.

(6) (a) Nakamura, E.; Aoki, S.; Sekiya, K.; Oshino, H.; Kuwajima, I. Carbon-Carbon Bond-Forming Reactions of Zinc Homoenolate of Esters. A Novel Three-Carbon Nucleophile with General Synthetic Utility. J. Am. Chem. Soc. 1987, 109, 8056-8066. (b) Das, P. P.; 
Belmore, K.; Cha, J. K. $\mathrm{S}_{\mathrm{N}} 2$ ' Alkylation of Cyclopropanols via Homoenolates. Angew. Chem. Int. Ed. 2012, 51, 9517-9520.

(7) Sekiguchi, Y.; Yoshikai, N. Enantioselective Conjugate Addition of Catalytically Generated Zinc Homoenolate. J. Am. Chem. Soc. 2021, 143, 4775-4781.

(8) Sekiguchi, Y.; Lee, Y. Y.; Yoshikai, N. Nickel-Catalyzed RingOpening Allylation of Cyclopropanols via Homoenolate. Org. Lett. 2021, DOI: 10.1021/acs.orglett.1c02072.

(9) (a) Noyori, R.; Suga, S.; Oka, H.; Kitamura, M. Self and Nonself Recognition of Chiral Catalysts: The Origin of Nonlinear Effects in the Amino-Alcohol Catalyzed Asymmetric Addition of Diorganozincs to Aldehydes. Chem. Rec. 2001, 1, 85-100. (b) Frantz, D. E.; Fassler, R.; Tomooka, C. S.; Carreira, E. M. The Discovery of Novel Reactivity in the Development of C-C Bond-Forming Reactions: In Situ Generation of Zinc Acetylides with $\mathrm{Zn}(\mathrm{II}) / \mathrm{R}_{3} \mathrm{~N}$. Acc. Chem. Res. 2000, 33, $373-$ 381 .

(10) Huang, W.; Meng, F. Cobalt-Catalyzed Diastereo- and Enantioselective Hydroalkylation of Cyclopropenes with Cobalt Homoenolates. Angew. Chem. Int. Ed. 2021, 60, 2694-2698.

(11) Chiba, S.; Cao, Z.; El Biary, S. A. A.; Narasaka, K. Generation of $\beta$-Keto Radicals from Cyclopropanols Catalyzed by $\mathrm{AgNO}_{3}$. Chem. Lett. 2006, 35, 18-19.

(12) (a) Enders, D.; Niemeier, O.; Henseler, A. Organocatalysis by N-Heterocyclic, Carbenes. Chem. Rev. 2007, 107, 5606-5655. (b) Marion, N.; Diez-Gonzalez, S.; Nolan, S. P. N-Heterocyclic Carbenes as Organocatalysts. Angew. Chem. Int. Ed. 2007, 46, 2988-3000. (c) Hopkinson, M. N.; Richter, C.; Schedler, M.; Glorius, F. An Overview of N-Heterocyclic Carbenes. Nature 2014, 510, 485-496. (d) Mahatthananchai, J.; Bode, J. W. On the Mechanism of N-Heterocyclic Carbene-Catalyzed Reactions Involving Acyl Azoliums. Acc. Chem. Res. 2014, 47, 696-707. (e) Flanigan, D. M.; Romanov-Michailidis, F.; White, N. A.; Rovis, T. Organocatalytic Reactions Enabled by NHeterocyclic Carbenes. Chem. Rev. 2015, 115, 9307-9387. 


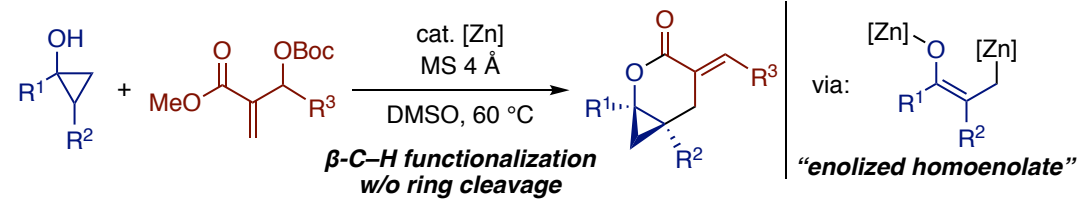

